\title{
Is Age-targeted full-field digital mammography screening cost-effective in emerging countries? A micro simulation model
}

\author{
Fabiano Hahn Souza ${ }^{1,2,3^{*}}$ and Carísi Anne Polanczyk ${ }^{1,2}$
}

\begin{abstract}
Objective: The present paper estimates the cost-effectiveness of population-based breast cancer (BC) screening strategies in Brazil for women under 50 years from the perspective of the Brazilian public health system.

Methods: A Markov model, simulating the natural history of female BC sufferers in Brazil, was developed. This model compares the lifetime effects, costs, and cost-effectiveness of seven BC screening strategies in women between 40 to 49 years: (A) usual care; (B) annual screen-film mammography (SFM); (C) SFM every 2 years; (D) annual full-field digital mammography (FFDM); (E) FFDM every 2 years; and ( $F$ and G) age-targeted options, with FFDM annually until 49 years and SFM annually (or biannually) from 50 to 69 years.
\end{abstract}

Results: Adopting SFM every 2 years (Strategy C) was found to be slightly more costly but also more effective in terms of quality-adjusted life years (QALYs), yielding an incremental cost-effectiveness ratio (ICER) of R\$ 1,509 per QALY gained. Annual SFM (Strategy B) was the next best option at an additional R\$13,131 per QALY gained. FFDM annual screening (Strategy E) was dominated by Strategy F, the age-targeted option. For younger women, the age-based strategy had an ICER of R\$30,520 per QALY gained. In the sensitivity analysis, the ICERs ranged from R\$ 15,300 to $R \$ 257,899$ in different regions of the country, depending on BC incidence, population age distribution, and mammography coverage.

Conclusions: SFM every 2 years for all women starting between the ages of 40 and 49 would be a cost-effective strategy. Taking into account regional specificities, age-targeted FFDM is one option to improve the outcomes of $\mathrm{BC}$ patients in an emerging country.

\section{Introduction}

Breast cancer $(\mathrm{BC})$ is the most frequently diagnosed cancer and the leading cause of cancer among females, accounting for $23 \%$ of total cancer diagnoses and $14 \%$ of overall cancer deaths (Jemal A et al. 2011). Moreover, $\mathrm{BC}$ is now the leading cause of cancer-related death among females in developing countries, a shift from the previous decade when cervical cancer was the most common cause of cancer-related death. Although cancer incidences and patterns differ according to level of human development, female $\mathrm{BC}$ is the only type of cancer that is common in all regions of the world. Thus, the

\footnotetext{
* Correspondence: hahnfabiano@hotmail.com

'Institute for Health Technology Assessment (IATS), Porto Alegre, RS, Brazil ${ }^{2}$ Graduate Studies Program in Epidemiology, School of Medicine, Federal University of Rio Grande do Sul, Porto Alegre, RS, Brazil

Full list of author information is available at the end of the article
}

global control of $\mathrm{BC}$ through both early detection and primary prevention is a high priority (Bray et al. 2012). Specifically in the context of this study, there is a high incidence of $\mathrm{BC}$ in the female population in Brazil with more than 50 new cases diagnosed per 100,000 women every year (INCA 2008).

Major advances in the early diagnosis of some cancers and a better understanding of the pathogenesis of the disease have led to risk reduction and prevention strategies. These advances as well as improvements in therapy have all contributed to declines in cancer-related death rates (Jemal et al. 2008). However, these successes have come with substantial increases in cost, causing a serious financial burden on patients, families, and society at large (Meropol et al. 2009). Currently, the most effective method for preventing premature mortality and morbidity due to $\mathrm{BC}$ is the increased use of screening programs and adjuvant 
therapies (Berry et al. 2005). In particular, effective early detection strategies are preferred to adjuvant therapies because they result in less morbidity.

For the past 30 years, conventional screen-film mammography (SFM) has been the method of choice for the radiological evaluation of the breast (Tabar \& Dean 2008). The demonstration of the efficacy of mammography in reducing BC mortality by approximately $15 \%$ in younger women ( $<50$ years) (Nelson et al. 2009) led to recommendations in some countries to introduce routine screening programs for this subgroup (Schopper \& de Wolf 2009). However, considerable controversy over whether screening is effective for women aged 40-49 years has halted the adoption of a broad screening approach. Further, because SFM has lower sensitivity mainly due to the greater breast density and higher rates of tumor growth in younger women (Buist et al. 2004), full-field digital mammography (FFDM) has been shown to be superior to SFM in this subgroup (Souza et al. 2013; Pisano et al. 2008; Skaane et al. 2007).

FFDM is based on a different technology, in which each exposure produces a digital image (Tice \& Feldman 2008). Although BC age-targeted screening (digital for women $<50$ years) is reasonably cost-effective in the US (Tosteson et al. 2008), no studies of the cost-effectiveness of FFDM screening in younger women have yet been carried out in middle-income countries. The objective of this study is thus to explore the cost-effectiveness of population-based $\mathrm{BC}$ screening using different strategies for women aged 40-49 years in the Brazilian public health system.

\section{Material and methods}

Mathematical model

The developed mathematical model was constructed using decision analysis software (TreeAgePro2009 Suite, release 1.0.2, Tree Age Software, Inc., Williamstown, MA). Specifically, a Markov model was used to compare populations of young women in Brazil. The structure of the model (Figure 1) is similar to other models used for BC screening programs and characterizes the complexity of the natural history of the disease (e.g., invasive stages are defined following the tumor-node-metastasis classification (Edge et al. 2010; van Oortmarssen et al. 1990; Szeto \& Devlin 1996; Rojnik et al. 2008).

In the real world, women diagnosed with $\mathrm{BC}$ have a relatively high risk of developing a new cancer or a recurrent disease. Women who develop a recurrent disease will create extra cost and utilities for the state in line with the basal risk of recurrence of the higher Markov state.

The micro simulation approach with a cycle length of 1 year with half-cycle correction was chosen for this study. BC incidence, mammography sensitivity, mortality, and relative survival rate were modeled as time-dependent transition probabilities.
We considered the following seven BC screening strategies for women aged 40-49 years: (A) usual care; (B) annual SFM; (C) SFM every 2 years; (D) annual FFDM; (E) FFDM every 2 years; (F) "age-targeted digital" (i.e., annual FFDM for the 40-49 age group and annual SFM for the 50-69 age group); and (G) "age-targeted digital" (annual FFDM for the 40-49 age group and SFM every 2 years for the 50-69 age group). These strategies were based on the findings of previous studies (Schopper \& de Wolf 2009; US Preventive Services Task Force 2009) and they included the current status of the Brazilian public health system (Strategy A "no formal BC screening" as the base case). According to DATASUS, the Brazilian public health system database, the annual utilization of SFM is approximately $17.5 \%$ in women above 50 years (Ministério_Saúde_Brasil, DATASUS 2011).

To determine whether the increased costs of screening strategies are warranted by health gains compared with usual care, we assessed the cost-effectiveness of these seven screening strategies from a public healthcare perspective. The time horizon covered the full lifetimes of the sample population from age 40 onward. Mammography screening stops after 69 years as recommended by the Brazilian National Cancer Institute (INCA) (INCA 2007). The starting age for the micro simulation ranged from 40 to 49 years based on the Brazilian population census (IBGE 2010).

\section{Model calibration}

Data on age-dependent cancer incidence were obtained from the Population-based Cancer Registry in Brazil (INCA 2010). The clinical-stage distributions for usual care and screening strategies were used from INCA (INCA 2011) and from the literature, respectively. Table 1 presents the main parameters used in the model.

Transitions to Markov states are governed by the rate of incidence, clinical-stage distribution data, and sojourn time. We modeled for an increase in the incidences of in situ carcinomas through the introduction of screening mammography (Kerlikowske 2010). Ten years after the introduction of these screening programs, ductal carcinoma in situ (DCIS) incidence rates were assumed to have stabilized.

Moreover, evidence of better prognostic screening compared with the pre-screening era for in situ cancer cases was incorporated into our model (Ernster et al. 2000), while over diagnosis was adjusted for confounding and lead time bias according to the findings of Smith and Duffy (Smith \& Duffy 2011). The risks and benefits of screening schedules were also adapted from Mandelblatt et al. (Mandelblatt et al. 2009). BC prognosis subgroups were then determined for advanced disease status: Luminal A, Luminal B, HER2-enriched, and triple negative (Kennecke et al. 2010). Screened BC has been shown 


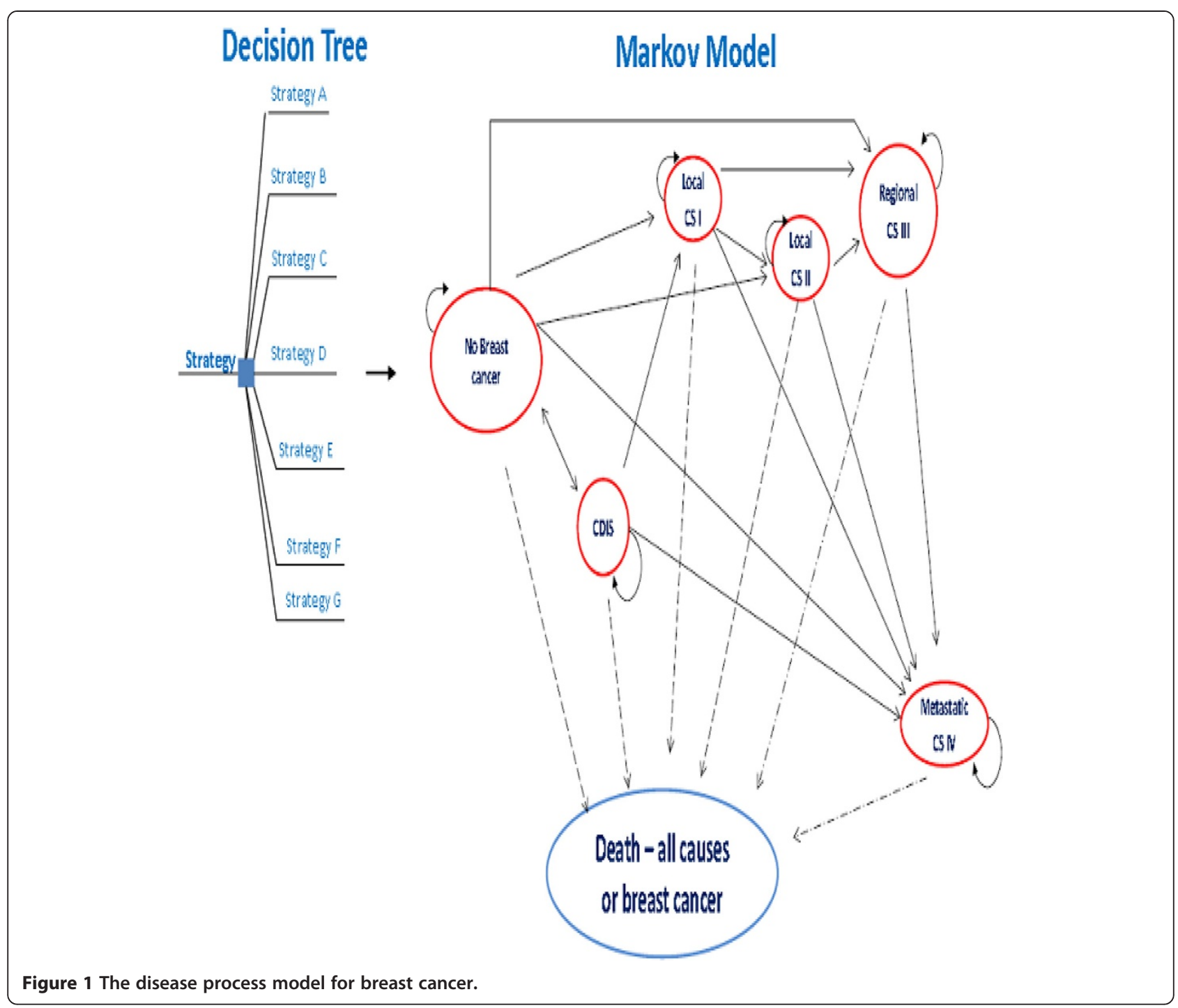

to have independently lower mortality rates compared with non-screened BC (Mook et al. 2011). Finally, we also adjusted BC recurrence risk based on BC subgroup, exposure to adjuvant/palliative chemotherapy, adjuvant/palliative trastuzumab, and adjuvant/palliative endocrine therapy based on previous findings (Perez et al. 2011; Hortobagyi 1998; Mauri et al. 2006; Mouridsen et al. 2003; Mouridsen et al. 2001; Slamon et al. 2001).

Patterns of stage-specific treatments were adapted from DATASUS and from the literature. For DCIS, two treatments were possible: surgery with or without radiotherapy (Wapnir et al. 2011; Baxter et al. 2004; Meijnen et al. 2008). For invasive BC, five treatments were possible: surgery, anti-HER2 adjuvant biologic therapy, radiotherapy, chemotherapy, and endocrine therapy. The last three treatments could be used in an adjuvant as well as in a palliative setting, while anti-HER2 therapy was only allowed in adjuvant stage 2 and 3 settings for
HER2-positive patients for 1 year (Perez et al. 2011). Further, the sensitivity of the mammography in the base case was adapted from Breast Cancer Surveillance Consortium (BCSC) data (Kerlikowske et al. 2011). The BCSC database was chosen because it is the largest source of effectiveness data from population screening using both film and digital technology.

The deployment of an FFDM screening program may cause higher recall rates compared with an SFM-based program (Bluekens et al. 2010). For the first round of screening in the present study (prevalence screening), recall rates were $4.29 \%$ and $3.41 \%$ for FFDM and SFM, respectively. For the second round (incidence screening), recall rates were $1.69 \%$ and $1.01 \%$ (Bluekens et al. 2010). We assumed that all recalled women would undergo another mammography and/or ultrasound. Approximately 5\% and $3 \%$ of the recalled women underwent fine needle aspiration and surgical biopsy, respectively (Moss et al. 2006). 
Table 1 Main parameters used in the base case and sensitivity analyses

\begin{tabular}{|c|c|c|c|c|c|}
\hline \multirow[t]{2}{*}{ Variables } & \multicolumn{3}{|c|}{ Screening test performance } & \multirow[t]{2}{*}{ Distribution/comments } & \multirow[t]{2}{*}{ Reference } \\
\hline & Mean & Minimum & Maximum & & \\
\hline Mammography coverage & $18 \%$ & $10 \%$ & $30 \%$ & Uniform & (Ministério_Saúde_Brasil, DATASUS 2011) \\
\hline Mammography coverage " & $70 \%$ & $55 \%$ & $85 \%$ & Uniform & (Lilliu et al. 2002) \\
\hline Sensitivity of SFM (40-49 years) & $76 \%$ & $60 \%$ & $85 \%$ & Effectiveness data from large population & (Kerlikowske et al. 2011) \\
\hline Sensitivity of FFDM (40-49 years) & $82 \%$ & $65 \%$ & $90 \%$ & Effectiveness data from large population & (Kerlikowske et al. 2011) \\
\hline Sensitivity of SFM (50-59 years) & $85 \%$ & $65 \%$ & $90 \%$ & Effectiveness data from large population & (Kerlikowske et al. 2011) \\
\hline Sensitivity of FFDM (50-59 years) & $80 \%$ & $65 \%$ & $90 \%$ & Effectiveness data from large population & (Kerlikowske et al. 2011) \\
\hline Sensitivity of SFM (60-69 years) & $83 \%$ & $65 \%$ & $90 \%$ & Effectiveness data from large population & (Kerlikowske et al. 2011) \\
\hline Sensitivity of FFDM (60-69 years) & $90 \%$ & $65 \%$ & $95 \%$ & Effectiveness data from large population & (Kerlikowske et al. 2011) \\
\hline Treatment complication (yearly) - Chemotherapy & $16 \%$ & $10 \%$ & $20 \%$ & Resource utilization database & (Hassett et al. 2006) \\
\hline Treatment complication (yearly) - Endocrine therapy & $5 \%$ & $1 \%$ & $10 \%$ & Resource utilization database & (Hassett et al. 2006) \\
\hline \multirow[t]{3}{*}{ Overdiagnosis } & $5 \%$ & 0 & $30 \%$ & Systematic review estimate & (Smith \& Duffy 2011) \\
\hline & \multicolumn{3}{|c|}{ Cancer stage distribution } & & \\
\hline & Mean & \multicolumn{2}{|c|}{$\mathrm{Cl}^{*} 95 \%$} & & \\
\hline DCIS (clinical diagnostic) & $6.1 \%$ & \multicolumn{2}{|c|}{$4.9-7.3 \%$} & Beta $(a=97 ; \beta=1494)$ & (INCA 2009b; Martins et al. 2009) \\
\hline State 1 (clinical diagnostic) & $14 \%$ & \multicolumn{2}{|c|}{$13.1-16.6 \%$} & Beta $(\alpha=232 ; \beta=1329)$ & (INCA 2009b; Martins et al. 2009) \\
\hline State 2 (clinical diagnostic) & $38.6 \%$ & \multicolumn{2}{|c|}{$36.5-40.5 \%$} & Beta $(\alpha=915 ; \beta=1455)$ & (INCA 2009b; Martins et al. 2009) \\
\hline State 3 (clinical diagnostic) & $34.7 \%$ & \multicolumn{2}{|c|}{$32.4-37.1 \%$} & Beta $(\alpha=546 ; \beta=1028)$ & (INCA 2009b; Martins et al. 2009) \\
\hline State 4 (clinical diagnostic) & $10.8 \%$ & \multicolumn{2}{|c|}{ NA } & Complementary & (INCA 2009b; Martins et al. 2009) \\
\hline CDIS (screening diagnostic) & $6.1 \%$ & \multicolumn{2}{|c|}{ NA } & Dynamic range $^{\text {S }}$ & (Kerlikowske et al. 2011) \\
\hline State 1 (screening diagnostic) & $58 \% \equiv$ & \multicolumn{2}{|c|}{ NA } & Effectiveness data from large population & (Kerlikowske et al. 2011) \\
\hline State 2 (screening diagnostic) & $32.4 \% \equiv$ & \multicolumn{2}{|c|}{ NA } & Effectiveness data from large population & (Kerlikowske et al. 2011) \\
\hline State 3 (screening diagnostic) & $8.3 \% \equiv$ & \multicolumn{2}{|c|}{ NA } & Effectiveness data from large population & (Kerlikowske et al. 2011) \\
\hline \multirow[t]{2}{*}{ State 4 (screening diagnostic) } & $1.3 \% \equiv$ & \multicolumn{2}{|c|}{ NA } & Effectiveness data from large population & (Kerlikowske et al. 2011) \\
\hline & \multicolumn{3}{|c|}{ Transition probabilities } & & \\
\hline BC Recurrence & Mean & Range & Local & Regional/systemic & \\
\hline CDIS & $0.008 / y$ & $0.002-0.014 / y$ & $50-98 \%$ & $2-50 \%$ & (Baxter et al. 2004; Meijnen et al. 2008) \\
\hline Stage 1 & $0.030 / y$ & NA & $16-47 \%$ & $53-84 \%$ & (Hirsch et al. 2011a; Hirsch et al. 2011b) \\
\hline Stage 2 & $0.087 / y$ & NA & $19-56 \%$ & $44-81 \%$ & (Wapnir et al. 2006) \\
\hline Stage 3 & $0.283 / y$ & $0,11-0,28 / y$ & $19-56 \%$ & $19-56 \%$ & (Wapnir et al. 2006) \\
\hline BC Death & Mean & Range & & & \\
\hline CDIS & $0.002 / y$ & $0.002-0.003 / y$ & & & (Ernster et al. 2000) \\
\hline Stage 1 & $0.009 / y$ & NA & & & (de Oliveira et al. 2009) \\
\hline Stage 2 & $0.031 / y$ & NA & & & (de Oliveira et al. 2009) \\
\hline
\end{tabular}

Cancer stage distribution 
Table 1 Main parameters used in the base case and sensitivity analyses (Continued)

\begin{tabular}{|c|c|c|c|c|c|}
\hline Stage 3 & $0.090 / y$ & NA & & & (de Oliveira et al. 2009) \\
\hline \multirow[t]{3}{*}{ Stage 4} & $0.270 / y$ & $0.20-0.34$ & & & (de Oliveira et al. 2009) \\
\hline & \multicolumn{2}{|c|}{ Relative risk } & \multicolumn{2}{|r|}{ Distribution/comments } & \\
\hline & \multicolumn{2}{|c|}{ Mean } & & & \\
\hline Adjuvant Taxane chemotherapy ${ }^{\S}$ & \multicolumn{2}{|c|}{0.86} & \multicolumn{2}{|r|}{ Log-Normal $(\mu=-0.15 ; \sigma=0.07)$} & (Peto et al. 2012) \\
\hline Adjuvant Aromatase inhibitor ${ }^{\text {sq }}$ & \multicolumn{2}{|c|}{0.82} & \multicolumn{2}{|r|}{ Log-Normal $(\mu=-0.20 ; \sigma=0.12)$} & (Dowsett et al. 2010) \\
\hline Adjuvant Trastuzumab therapy ${ }^{\S \ddagger}$ & \multicolumn{2}{|c|}{0.61} & \multicolumn{2}{|r|}{ Log-Normal $(\mu=-0.49 ; \sigma=0.06)$} & (Perez et al. 2011) \\
\hline Screening vs. non-screening cancer cases ${ }^{\Phi}$ & \multicolumn{2}{|c|}{0,62} & \multicolumn{2}{|r|}{ Log-Normal $(\mu=-0.48 ; \sigma=0.12)$} & (Mook et al. 2011) \\
\hline Advanced disease - Luminal A vs. Luminal $B^{*}$ & \multicolumn{2}{|c|}{1.42} & \multicolumn{2}{|r|}{ Log-Normal $(\mu=0.34 ; \sigma=0.12)$} & (Kennecke et al. 2010) \\
\hline Advanced disease - Luminal A vs. HER2 $+{ }^{*}$ & \multicolumn{2}{|c|}{1.90} & \multicolumn{2}{|r|}{ Log-Normal $(\mu=0.64 ; \sigma=0.11)$} & (Kennecke et al. 2010) \\
\hline \multirow[t]{3}{*}{ Advanced disease - Luminal A vs. Triple negative ${ }^{¥}$} & \multicolumn{2}{|c|}{1.62} & \multicolumn{2}{|r|}{ Log-Normal $(\mu=0.48 ; \sigma=0.11)$} & (Kennecke et al. 2010) \\
\hline & \multicolumn{2}{|c|}{ Relative odds ratio } & \multicolumn{2}{|r|}{ Distribution/comments } & \\
\hline & \multicolumn{2}{|c|}{ Mean } & & & \\
\hline \multirow[t]{2}{*}{ Diagnostic cancer downstage (FFDM under 50 years) } & \multicolumn{2}{|c|}{0.54} & \multicolumn{2}{|r|}{ Log-Normal $(\mu=-0.654 ; \sigma=0.307)$} & (Souza et al. 2013) \\
\hline & Mean & Minimum & Maximum & & \\
\hline \multirow[t]{3}{*}{ Discount rate } & $5 \%$ & $0 \%$ & $10 \%$ & Brazilian Health Economic Guidelines & (Ministério_Saúde_Brasil 2009) \\
\hline & \multicolumn{4}{|c|}{ Costs (Brazilian Real) } & \\
\hline & Mean & Minimum & Maximum & & \\
\hline Medical visit & 10 & 5 & 25 & DATASUS & (Ministério_Saúde_Brasil, DATASUS 2011) \\
\hline FFDM & 68 & 45 & 90 & Estimated $^{\forall}$ & (Souza 2012) \\
\hline SFM & 45 & 30 & 60 & DATASUS & (Ministério_Saúde_Brasil, DATASUS 2011) \\
\hline Biopsy & 429 & 150 & 700 & Gamma $(a=14.93 ; \lambda=0.03)$ & (Souza 2012) \\
\hline Recall SFM & 152 & 50 & 250 & Aggregate costs & (Souza 2012) \\
\hline Recall FFDM & 197 & 100 & 300 & Aggregate costs & (Souza 2012) \\
\hline Staging early $\mathrm{BC}^{\psi}$ & 509 & 250 & 750 & Gamma ( $a=3.09 \lambda=0.01)$ & (Souza 2012) \\
\hline Staging locally and advanced cancer $^{\Delta}$ & 592 & 200 & 800 & Gamma $(a=2.52 \lambda=0.04)$ & (Souza 2012) \\
\hline Invasive cancer stage 1 (first year) & 6,502 & 2,500 & 11,500 & Aggregate costs & (Souza 2012) \\
\hline Invasive cancer stage 2 (first year) & 15,610 & 6,500 & 24,500 & Aggregate costs & (Souza 2012) \\
\hline Invasive cancer stage 3 (first year) & 18,638 & 9,500 & 27,500 & Aggregate costs & (Souza 2012) \\
\hline Invasive cancer stage 4 (first year) & 12,452 & 6,500 & 20,500 & Aggregate costs & (Souza 2012) \\
\hline Invasive cancer stage 1 ( $\geq 2$ year) & 602 & 200 & 1,000 & Aggregate costs & (Souza 2012) \\
\hline Invasive cancer stage 2 ( $\geq 2$ year) & 677 & 200 & 1,200 & Aggregate costs & (Souza 2012) \\
\hline Invasive cancer stage 3 ( $\geq 2$ year) & 742 & 200 & 1,600 & Aggregate costs & (Souza 2012) \\
\hline Invasive cancer stage 4 ( $\geq 2$ year) & 12,439 & 4000 & 20,000 & Aggregate costs & (Souza 2012) \\
\hline
\end{tabular}


Table 1 Main parameters used in the base case and sensitivity analyses (Continued)

\begin{tabular}{|c|c|c|c|c|}
\hline \multicolumn{3}{|c|}{ Utilities } & & \\
\hline & Mean & $\mathrm{Cl}^{*} 95 \%$ & & \\
\hline Healthy woman & 0.800 & NA & South of Brazil population ${ }^{\perp}$ & (Cruz 2010) \\
\hline Healthy woman - false positive mammography & 0.795 & NA & Estimated & (Cruz 2010) \\
\hline Non metastatic $\mathrm{BC}^{\mathrm{X}}$ - follow-up & 0.772 & $0.63-0.90$ & Normal distribution & (Souza 2012; Cruz 2010) \\
\hline Early $B C^{X}$ - Adjuvant Endocrine Therapy & 0.762 & $0.62-0.91$ & Normal distribution & (Souza 2012; Cruz 2010) \\
\hline Early $B C^{X}$ - Adjuvant Chemotherapy & 0.739 & $0.61-0.87$ & Normal distribution & (Cruz 2012; Cruz 2010) \\
\hline Clinical Stage 3 - Adjuvant Endocrine Therapy & 0.760 & $0.59-0.95$ & Normal distribution & (Souza 2012; Cruz 2010) \\
\hline Clinical Stage 3 - Adjuvant Chemotherapy & 0.700 & $0.63-0.78$ & Normal distribution & (Souza 2012; Cruz 2010) \\
\hline Clinical Stage 4 - Advanced disease & 0.680 & $0.57-0.80$ & Normal distribution & (Souza 2012; Cruz 2010) \\
\hline
\end{tabular}

"Screening strategies; NA: not applicable; ${ }^{j}$ time and screening coverage-dependent (increase in the DCIS rate with the introduction of the screening program): ${ }^{\equiv}$ relative to invasive cancer (excluding DCIS); ${ }^{\S}$ Relative risk of BC death in clinical stage 2 and 3 patients; ${ }^{\natural}$ hormone-positive patients; ${ }^{\ddagger}$ HER2-positive patients; ${ }^{\Phi}$ Relative risk of BC death; ${ }^{*}$ Relative risk of BC death in advanced disease (stage 4 ) according to prognostic subtype; ${ }^{*}$ Plausible estimate $50 \%$ above SFM reimbursement value; ${ }^{\psi}$ clinical stages 1 and $2 ;{ }^{\Delta}$ clinical stages 3 and $4 ;{ }^{*}$ confidence interval; ${ }^{\perp}$ Porto Alegre city; ${ }^{\circ}$ Considering the mean of non-metastatic BC utility $(0.77)$ and a false positive as a 2-month period of disutility $\left(0.80-0.77=\left[(0.03)^{*}(0.16\right.\right.$ year $\left.)=0.005\right] \rightarrow 0.80-0.005=0.795{ }^{*}$ in situ, stage 1 , stage 2 , and stage 3 patients. 
All death rates were adapted from the Brazilian Institute of Geography and Statistics Census (2010) and BC deaths were calibrated based on the Mortality Information System of Brazil (DATASUS 2000).

We tested whether the model was calibrated according to the life expectancy of Brazilian women (IBGE 2010). The model does not include input parameters for life expectancy, which is estimated indirectly as a function of the parameters for relapse rates, progression, and overall and BC deaths. Thus, the life expectancy of Brazilian women was defined as an appropriate parameter to validate the model in Brazil. Figure 2 presents the life expectancy predicted in the model at a $95 \%$ confidence interval.

\section{Screening and participation rates}

There is no formal screening activity in Brazil (despite some isolated initiatives at a regional level). Therefore, opportunistic screening is considered to be usual care in the Brazilian public health system. DATASUS shows that approximately $18 \%$ of women above 50 have undergone SFM (Ministério_Saúde_Brasil, DATASUS 2011). A Brazilian prospective cohort achieved a similar opportunistic screening rate of approximately 24\% (Marchi \& Gurgel 2010). Finally, annual participation rates ranged from $18 \%$ to $70 \%$.

\section{Costs and health outcomes}

Table 1 presents the costs and utilities applied in the model. Total costs consist of the costs of primary care consultancy, mammography screening, additional work-up exams (when required), cancer diagnostic procedures (images, biopsy, pathology), cancer staging (images), cancer treatment (surgery, radiotherapy, chemotherapy, anti-HER2, and endocrine therapy), and cancer follow-up. Costs were obtained from Ministério_Saúde_Brasil, DATASUS
(2011) and the BC database of resource utilization in the public healthcare system in Brazil (Souza 2012). All costs are expressed in 2010 Brazilian Real (US\$ $1=\mathrm{R} \$ 1.67$ ). Quality-adjusted life years (QALYs) were estimated based on the patient's SF-6D scores (Souza 2012; Cruz 2010).

\section{Base case analysis}

Using a set of natural history input parameters, we calculated the expected costs and effectiveness of each strategy in base case and sensitivity analyses. The costs and effects of each simulated screening program were then assessed. Future costs and health effects (e.g., life years and utilities losses) were discounted at a rate of $5 \%$ according to the Brazilian Guidelines for Health Technology Assessment (Ministério_Saúde_Brasil 2009). After ranking them in order of increasing costs and eliminating all dominant strategies (greater cost and fewer benefits than any other combination of strategies), we calculated incremental costeffectiveness ratios (ICERs).

Since there is no recommended threshold to determine whether an intervention is cost-effective in Brazil (Ministério_Saúde_Brasil 2009), we adapted the recommendations of the World Health Organization, which suggests that a cost-effective intervention would avert one additional disability-adjusted life year for less than three times average per capita GDP (World Health Organization 2001). We assumed that society's willingness to pay (WTP) for one additional disability-adjusted life year was equivalent to its WTP for one QALY. This approach has been used in previous economic evaluations performed in Brazil and in other middle-income countries (Goldie et al. 2007; Goldie et al. 2008; Vanni et al. 2010; Vanni et al. 2012). Programs that were more costly and less effective than other programs were immediately ruled out as inefficient

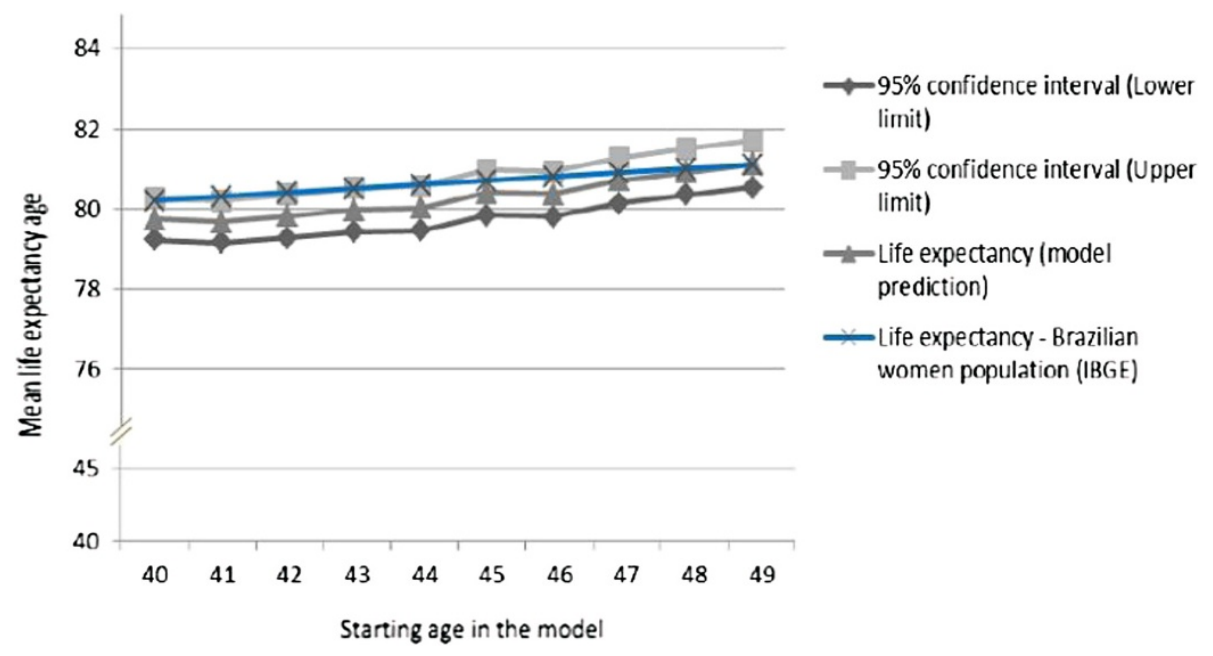

Figure 2 Model predicted life expectancy and 95\% confidence interval for women $\mathbf{4 0}$ years and older, and estimates from the Brazilian Institute of Geography and Statistics Cencus. 
(i.e., according to the simple dominance principle). The remaining programs constituted the frontier of efficient screening programs.

\section{Sensitivity analysis}

To assess uncertainty in the model, one-way, scenario, and probabilistic sensitivity analyses were conducted. In one-way sensitivity analysis, the key parameters were varied using minimum and maximum values, as shown in Table 1. A probabilistic sensitivity analysis was also performed to explore joint uncertainty across parameters. By sampling the distribution of the model parameters, we generated 10,000 estimates for the costs and effects of each strategy. These estimates were plotted on a costeffectiveness plane and cost-effectiveness acceptability curves were used to depict the level of uncertainty for the optimal strategy at different WTP thresholds for an additional QALY (Barton et al. 2008).

\section{Results}

\section{Base case analysis}

In the base case analysis, with a simulated cohort starting at 40 years, we found that the mean survival period (adjusted for quality) for usual care was 14,498, at a lifetime cost of $R \$ 2,075$. All other screening strategies were associated with higher QALYs and additional costs. Table 2 presents the ICER results for the base case analysis. The discounted QALYs for the seven strategies were similar to those found in previous BC screening studies, while the differences between these strategies were small (Tosteson et al. 2008; Rojnik et al. 2008). However, there were greater differences in terms of expected lifetime costs.

Thus, the costs and effectiveness of the strategies were considered to identify which strategy represented better value for money. Figure 3 and Table 2 show that usual care (Strategy A) was the cheapest but least effective strategy. Adopting SFM every 2 years (Strategy C) was slightly more costly but also more effective, yielding an ICER of R\$1,509 per QALY gained. The next best alternative also adopted SFM, but now annually (Strategy B), which was cost-effective at an additional R\$13,131 per QALY gained. FFDM annual screening (Strategy E) was dominated by Strategy F, which is an age-targeted option, with FFDM used annually until 49 years and SFM annually from 50 to 69 years. For younger women ( $<50$ years), this is the most effective strategy. With an ICER of R \$ 30,520, Strategy F could also be considered to be a cost-effective strategy for an emerging country such as Brazil.

\section{Sensitivity analysis}

In the one-way sensitivity analysis, the ranking of the seven strategies remained unchanged for most model parameters. The results were most sensitive to changes in the coverage of opportunistic screening under usual care (Strategy A). At a coverage rate of approximately $30 \%$, SFM every 2 years showed cost savings. Although the discount rate and BC incidence seemed to play an important role in determining the magnitude of ICERs, they did not change the order of the strategies that composed the cost-effectiveness frontier.

Figure 4 presents the range of ICERs according to $\mathrm{BC}$ incidence, age distribution, and mammography coverage by Brazilian region (INCA 2010; MS 2011). In regions that have a lower BC incidence (e.g., Belem and Cuiaba city), ICERs have a higher probability of not being cost-effective ( $\mathrm{R} \$ 257,889$ and $\mathrm{R} \$ 49,362$, respectively). On the contrary, for regions that have a higher BC incidence (e.g., São Paulo and Recife), the ICER is approximately $R \$ 21,000$. The best scenario was in Porto Alegre, with an ICER of R\$ 15,300.

Figure 5 reports the results of the probabilistic sensitivity analysis. By adopting the threshold suggested by the Commission for Macroeconomics in Health for costeffectiveness interventions (R\$ 17,869/QALY), and by considering both SFM strategies (annual and every 2 years), we found a high probability that SFM is a cost-effective approach for the Brazilian public health system (approximately $70 \%$ of the simulations). Moreover, at a much lower ICER of R\$ 6,000/QALY, SFM every 2 years was costeffective in more than $95 \%$ of the simulations.

Nonetheless, it is important to recognize that FFDM is increasingly used by institutions in Brazil. When we consider a cost-effective threshold of three times national GDP (R\$ 53,607/QALY), we found a high probability

Table 2 Base-case incremental cost effectiveness results

\begin{tabular}{|c|c|c|c|c|}
\hline Strategy & $\begin{array}{l}\text { Discounted costs } \\
\text { (Brazilian Real) }\end{array}$ & $\begin{array}{l}\text { Discounted } \\
\text { effect (QALY) }\end{array}$ & $\begin{array}{l}\text { Order of non-dominated } \\
\text { strategies }\end{array}$ & ICER (R\$/QALY) \\
\hline Strategy A - Usual care & 2,075 & 14,498 & 1 & - \\
\hline Strategy B - SFM annual & 2,318 & 14,546 & 3 & 13,131 \\
\hline Strategy C - SFM every 2 years & 2,125 & 14,532 & 2 & 1,509 \\
\hline Strategy D - FFDM annual & 2,564 & 14,548 & & \\
\hline Strategy E - FFDM every 2 years & 2,259 & 14,533 & & \\
\hline Strategy F - FFDM $(<50)$ and SFM $(50-69)$ annual & 2,393 & 14,549 & 4 & 30,520 \\
\hline $\begin{array}{l}\text { Strategy F - FFDM annual }(<50) \text { and SFM } \\
(50-69) \text { every } 2 \text { years }\end{array}$ & 2,254 & 14,538 & & \\
\hline
\end{tabular}




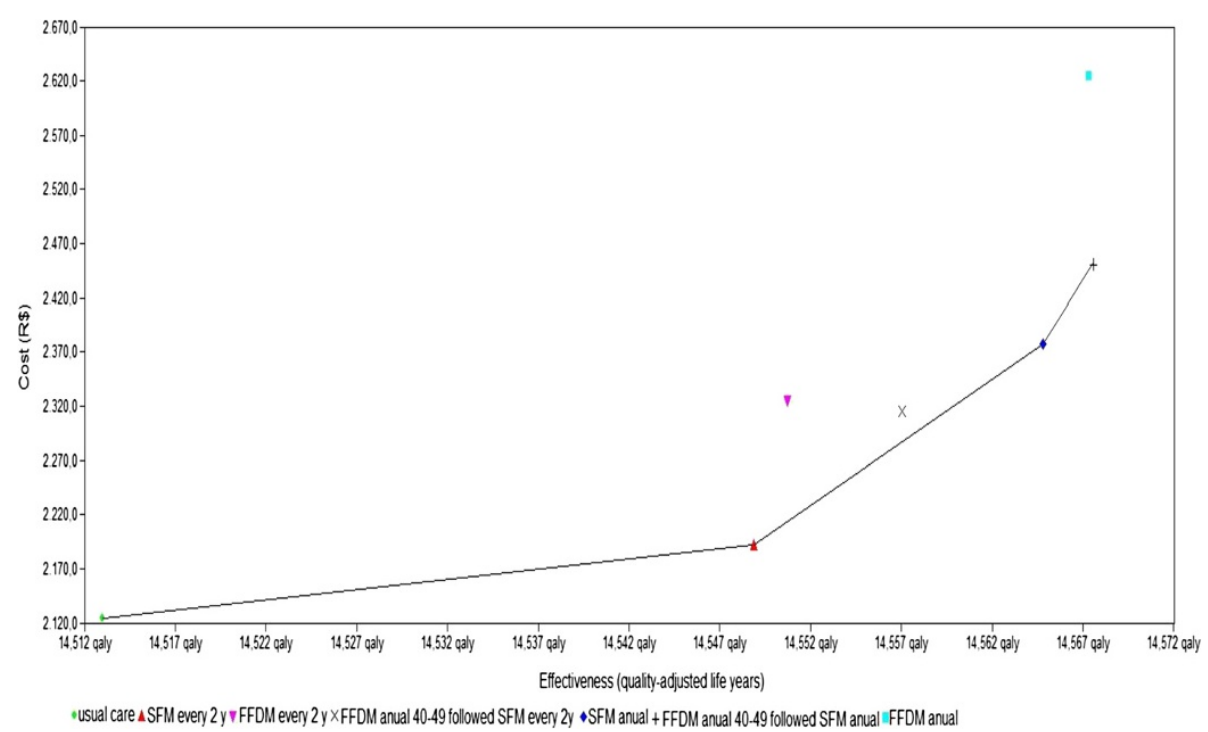

Figure 3 Cost Effectiveness plane (base-case).

that an age-targeted strategy (e.g., Strategy F) would be cost-effective (approximately 60\% of the simulations). Considering a WTP of R $20,000 /$ QALY, $10 \%$ of the simulations with Strategy F would be considered to be cost-effective. In the case of a WTP of R\$100,000/QALY, this figure grew to $70 \%$ of the simulations.

\section{Discussion}

$\mathrm{BC}$ incidence varies considerably throughout the world; indeed, age-standardized incidence is approximately fourfold higher in high-income countries in North America and Western Europe compared with countries that have a lower per capita income (Legorreta et al. 1996).

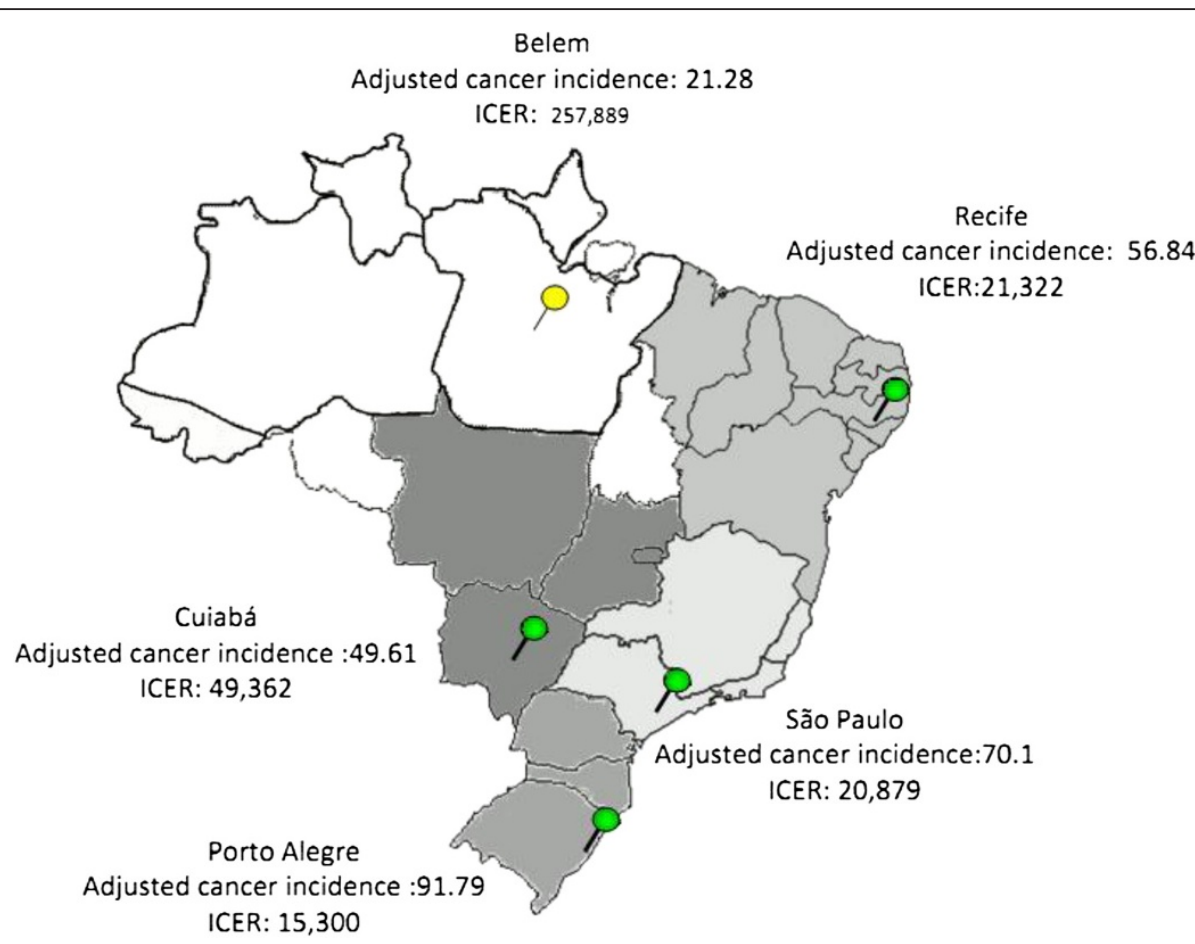

Figure 4 Sensitivity analysis. Shown is the range of the incremental cost-effectiveness ratios (ICERs) as a result of varying parameters and assumptions for screening strategy (breast cancer incidence, populational age distribution and mammography coverage). 


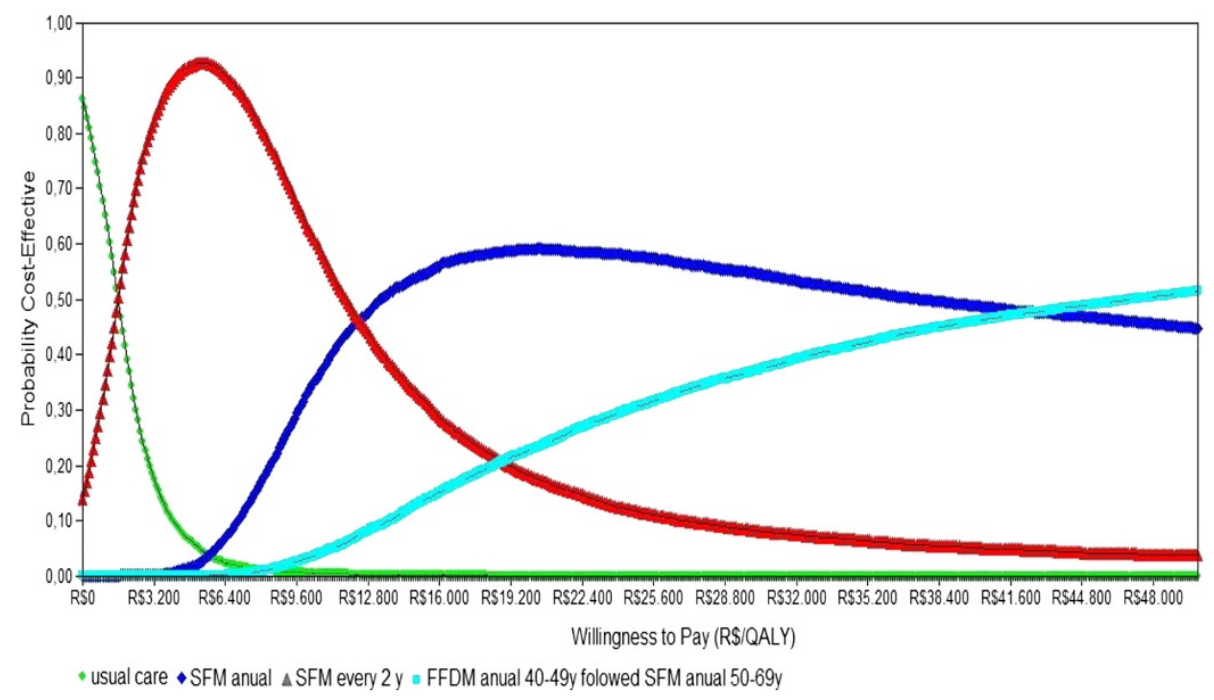

Figure 5 Cost Effectiveness acceptability curve (dominated strategies not shown).

A strong correlation between the age-standardized incidence of BC and average GDP per capita has been demonstrated (Lilliu et al. 2002). However, in many low- and middle-income countries, incidence is increasing faster than that in developed nations, where incidence is already high (Cody 1996).

In many Western countries, mammography screening has become the standard of care for the early detection of BC. Despite its widespread use, however, mammography is a far from a perfect means of early detection. Several limitations have been recognized, such as in the areas of false positive results, ethnic and biological differences, social and cultural barriers, and the harm-to-benefit ratio (Lu et al. 2012). Some studies have demonstrated that SFM can be cost-effective in Western countries (<US\$ 50,000/QALY) (Tosteson et al. 2008; Szeto \& Devlin 1996; Lindfors \& Rosenquist 1995), whereas its benefit is more questionable in low- and middleincome countries (Rojnik et al. 2008; Okonkwo et al. 2008; Jakubowski et al. 1996).

Our Markov model shows that using SFM to screen for $\mathrm{BC}$ is a cost-effective strategy for the public health system in Brazil, a middle-income country. Considering the cost-effective threshold given by Brazil's GDP per capita, SFM every 2 years is the strategy that has the best cost-effectiveness profile (ICER below the threshold and high probability of being cost-effective in the probabilistic sensitivity analysis). Gains in QALYs are likely to occur due to the earlier diagnostic stage of BC in women, which compensates for the additional cost of mammography screening, medical consultations, false positive results, the increase in the incidence of DCIS after the screening program has been deployed, and the over diagnosis of cancer cases. This $\mathrm{BC}$ treatment strategy allows for a better cure rate and lower expenses and health resource utilization (Legorreta et al. 1996; Lilliu et al. 2002; Lu et al. 2012; Butler et al. 1995; Hillner 1996; Cady 1996).

An important strength of our model is the use of the $\mathrm{BC}$ database, which reflects the standards of care in disease management. The base case reflects the life expectancy of Brazilian women, and QALYs were estimated from BC patients. QALYs for a healthy state were calculated based on the Brazilian population (Cruz 2010).

According to a recent government estimate, Brazil has enough mammography devices to cover more than $70 \%$ of Brazilian women aged above 50 years (MS 2011). Further, the country has deployed a program to improve the quality of mammograms in the Brazilian public health system (INCA 2009a). This adequate screening capacity along with a quality program and cost-effective data make the adoption of a national BC screening program feasible and desirable in Brazil. In this study, we demonstrate that a BC film-screening program every 2 years is a cost-effective strategy.

Regarding digital mammography screening strategies, annual screening by FFDM (Strategy E) was dominated by Strategy F (age-targeted screening). As presented in Figure 4, there was great variability in ICERs across the country, mainly related to local $\mathrm{BC}$ incidence. This finding suggests the importance of recognizing that for a large heterogeneous country as Brazil regionalized health policy must be considered by decision makers. For instance, in the north, digital mammography screening should not be recommended due to unfavorable cost-effectiveness. By contrast, in the southeast and south of the country, where $\mathrm{BC}$ incidences are higher, a digital age-targeted screening program could be considered to be a good investment in terms of value of money. 
Moreover, if we consider that most mammography machines in public institutions are obsolete ( $>8$ years old), the acquisition of replacement equipment is crucial. Thus, health policies that incentivize the acquisition of digital technology devices must be discussed for those regions with high $\mathrm{BC}$ incidence (mainly the southeast, south, and some areas of the northeast). In our view, this implementation should be gradual in order to minimize the budget impact from a short-term perspective, but it would allow the public system to move towards more modern technology. Although the main advantage of FFDM is seen for younger women ( $<50$ years), other potential benefits of digitalization could be anticipated, such as the possibility of teleradiology and the more reliable retrieval of exams for future comparisons.

Our model estimates of incremental QALYs are similar to those reported in previous studies in high-income countries (Tosteson et al. 2008; Szeto \& Devlin 1996; Lindfors \& Rosenquist 1995), and we draw similar conclusions about the advantages of $\mathrm{BC}$ screening in the younger population. To the best of our knowledge, however, this is the first cost-effectiveness analysis that focuses on age-targeted digital mammography screening for women above 40 years in low- and middle-income countries and that presents a feasible strategy for an emerging country. We believe that these results can be adapted to other emerging countries with similar $\mathrm{BC}$ incidence rates and public healthcare structures.

In conclusion, SFM every 2 years for all women starting between the ages of 40 and 49 would be a costeffectiveness strategy to be incorporated by the Brazilian public healthcare system. Taking into account regional specificities, age-targeted digital screening is one option to improve the outcomes of $\mathrm{BC}$ patients in an emerging country.

\section{Competing interests}

The authors declare that they have no competing interests.

\section{Authors' contributions}

Conception and design: FHS and CAP. Collection and assembly data: FHS. Data analysis and interpretation: FHS and CAP. Manuscript writing: FHS and CAP. Both authors read and approved the final manuscript.

\section{Acknowledgment}

The study was supported by a grant from the MCT/CNPq/MS-SCTIE-DECIT. The authors thank our supporter's institutions.

\section{Author details}

${ }^{1}$ Institute for Health Technology Assessment (IATS), Porto Alegre, RS, Brazil. ${ }^{2}$ Graduate Studies Program in Epidemiology, School of Medicine, Federal University of Rio Grande do Sul, Porto Alegre, RS, Brazil. ${ }^{3}$ Radiology and Oncology Department of the State of São Paulo Cancer Institute, University of São Paulo, Medical School, São Paulo, SP, Brazil.

Received: 18 July 2013 Accepted: 18 July 2013

Published: 31 July 2013

\section{References}

Barton GR, Briggs AH, Fenwick EA (2008) Optimal cost-effectiveness decisions: the role of the cost-effectiveness acceptability curve (CEAC), the cost-effectiveness acceptability frontier (CEAF), and the expected value of perfection information (EVPI). Value in Health 11(5):886-897

Baxter NN, Virnig BA, Durham SB, Tuttle TM (2004) Trends in the treatment of ductal carcinoma in situ of the breast. J Natl Cancer Inst 96(6):443-448

Berry DA, Cronin KA, Plevritis SK, Fryback DG, Clarke L, Zelen M, et al. (2005) Effect of screening and adjuvant therapy on mortality from breast cancer. N Engl J Med 353(17):1784-1792

Bluekens AM, Karssemeijer N, Beijerinck D, Deurenberg JJ, van Engen RE, Broeders MJ, et al. (2010) Consequences of digital mammography in population-based breast cancer screening: initial changes and long-term impact on referral rates. Eur Radiol 20(9):2067-2073

Bray F, Jemal A, Grey N, Ferlay J, Forman D (2012) Global cancer transitions according to the human development index (2008-2030): a population-based study. Lancet Oncol 13(8):790-801

Buist DS, Porter PL, Lehman C, Taplin SH, White E (2004) Factors contributing to mammography failure in women aged $40-49$ years. J Natl Cancer Inst 96 (19):1432-1440

Butler JR, Furnival CM, Hart RF (1995) Estimating treatment cost functions for progressive diseases: a multiproduct approach with an application to breast cancer. J Health Econ 14(3):361-385

Cady B (1996) Cost-effective preoperative evaluation, operative treatment, and postoperative follow-up in the breast cancer patient. Surg Clin North Am 76(1):25-34

Cody B (1996) An ethnohistory of a granny midwife. J Transcultural Nurs 8(1):13-18

Cruz LN (2010) Medidas de Qualidade de Vida e Utilidade em uma Amostra da População de Porto Alegre. Thesis (PhD in Epidemiology) Federal University of Rio Grande do Sul (. UFRGS), Porto Alegre, Brazil

DATASUS (2000) Sistema de Informação sobre Mortalidade (SIM) 1996-2000. Ministério da Saúde, Brazil

de Oliveira B, Lombardo V, Gotlieb SLD, de Souza JMP (2009) Sobrevida de Pacientes com Câncer no Estado de São Paulo: Seis Anos de Seguimento pelo Registro Hospitalar de Câncer, F.O.d.S.P. FOSP, Secretária de Estada da Saúde de São Paulo, São Paulo, Brazil

Dowsett M, Cuzick J, Ingle J, Coates A, Forbes J, Bliss J, et al. (2010) Meta-analysis of breast cancer outcomes in adjuvant trials of aromatase inhibitors versus tamoxifen. J Clin Oncol 28(3):509-518

Edge SB, Byrd DR, Compton CC (2010) AJCC (American joint committee on cancer) cancer staging manual, 7th edition. Springer-Verlag, New York

Ernster VL, Barclay J, Kerlikowske K, Wilkie H, Ballard-Barbash R (2000) Mortality among women with ductal carcinoma in situ of the breast in the population-based surveillance, epidemiology and end results program. Arch Intern Med 160(7):953-958

Goldie SJ, Kim JJ, Kobus K, Goldhaber-Fiebert JD, Salomon J, O'Shea MK, et al. (2007) Cost-effectiveness of HPV 16, 18 vaccinations in Brazil. Vaccine 25(33):6257-6270

Goldie SJ, Diaz M, Kim SY, Levin CE, Van Minh H, Kim JJ (2008) Mathematical models of cervical cancer prevention in the Asia Pacific region. Vaccine 26 (Suppl 12):M17-M29

Hassett MJ, O'Malley AJ, Pakes JR, Newhouse JP, Earle CC (2006) Frequency and cost of chemotherapy-related serious adverse effects in a population sample of women with breast cancer. J Natl Cancer Inst 98(16):1108-1117

Hillner BE (1996) Economic and cost-effectiveness issues in breast cancer treatment. Semin Oncol 23(1 Suppl 2):98-104

Hirsch A, Kachnic LA, Sabel MS, In: UpToDate (2011a) Management of locoregional recurrence of breast cancer after breast conserving therapy. Gralow, JR (Ed), UpToDate, Waltham, MA

Hirsch A, Kachnic LA, Sabel MS, Hayes D, In: UpToDate (2011b) Management of locoregional recurrence of breast cancer after mastectomy. Gralow, JR (Ed), UpToDate, Waltham, MA

Hortobagyi GN (1998) Treatment of breast cancer. N Engl J Med 339(14):974-984 IBGE (2010) XII Censo Demográfico. IBGE, Editor, Brazil

INCA (2007) Mamografia: da prática ao controle. Recomendações para profissionais de saúde. Ministério da Saúde, Rio de Janeiro, Brazil

INCA (2008) Estimativa da incidência de Câncer para 2008 no Brasil e nas cinco Regiões. http://www.inca.gov.br/conteudo_view.asp?id=1793. Jul 24, 2013

INCA (2009a) Publisher name. Programa de Qualidade em Mamografia - PQM, Ministério da Saúde do Brasil. http://www.inca.gov.br/releases/ press_release_view.asp?|D=2032 
INCA (2009b) Ministério da Saúde do Brasil. O Câncer de Mama no Brasil - Situação Epidemiológica e rastreamento, in Encontro interncional sobre rastreamento de câncer de mama, Rio de Janeiro, Brazil

INCA (2010) Câncer no Brasil. Dados dos Registros de Base Populacional, C.d.P.e. Vigilância, Editor 2010, Ministério da Saúde, Rio de Janeiro, Brazil. Câncer no Brasil: Dados dos Registros de Base Populacional

INCA (2011) Panorama da Assistência Oncológica no Sistema Único de Saúde a partir das Informações do Integrador RHC, D.d.l.e.A.d. Situação. Coordenação Geral de Ações Estratégicas, Rio de Janeiro, Brazil

Jakubowski AA, et al. (1996) Phase I study of continuous-infusion recombinant macrophage colony-stimulating factor in patients with metastatic melanoma. Clin Can Res 2(2):295-302

Jemal A, Siegel R, Ward E, Hao Y, Xu J, Murray T, et al. (2008) Cancer statistics, 2008. CA Cancer J Clin 58(2):71-96

Jemal A, Bray F, Center MM, Ferlay J, Ward E, Forman D (2011) Global cancer statistics. CA Cancer J Clin 61(2):69-90

Kennecke H, Yerushalmi R, Woods R, Cheang MC, Voduc D, Speers CH, et al. (2010) Metastatic behavior of breast cancer subtypes. J Clin Oncol 28(20):3271-3277

Kerlikowske K (2010) Epidemiology of ductal carcinoma in situ. J Natl Cancer Inst Monogr 41:139-141

Kerlikowske K, Hubbard RA, Miglioretti DL, Geller BM, Yankaskas BC, Lehman CD, et al. (2011) Comparative effectiveness of digital versus film-screen mammography in community practice in the United States: a cohort study. Ann Intern Med 155(8):493-502

Legorreta AP, Brooks RJ, Leibowitz AN, Solin $\sqcup$ (1996) Cost of breast cancer treatment. A 4-year longitudinal study. Arch Intern Med 156(19):2197-2201

Lilliu H, Stevens D, Brun C, Morel J, Pen CL, Bonastre J, et al. (2002) Cost of treatment and follow up of breast cancer: a retrospective assessment in a comprehensive cancer centre. Bulletin du Cancer 89(6):635-642

Lindfors KK, Rosenquist CJ (1995) The cost-effectiveness of mammographic screening strategies. JAMA 274(11):881-884

Lu W, Greuter MJ, Schaapveld M, Vermeulen KM, Wiggers T, de Bock GH (2012) Safety and cost-effectiveness of shortening hospital follow-up after breast cancer treatment. Brit J Surg 99(9):1227-1233

Mandelblatt JS, Cronin KA, Bailey S, Berry DA, de Konnig HJ, Draisma G, et al. (2009) Effects of mammography screening under different screening schedules: model estimates of potential benefits and harms. Ann Intern Med 151(10):738-747

Marchi AA, Gurgel MS (2010) Adherence to the opportunistic mammography screening in public and private health systems. Rev Bras Ginecol Obstet 32(4):191-197

Martins E, Freitas R, Jr, Curado MP (2009) Temporal evolution of breast cancer stages in a population-based cancer registry in the Brazilian central region. Rev Bras Ginecol Obstet 315(5):5

Mauri D, Pavlidis N, Polyzos NP, loannidis JP (2006) Survival with aromatase inhibitors and inactivators versus standard hormonal therapy in advanced breast cancer: meta-analysis. J Natl Cancer Inst 98(18):1285-1291

Meijnen P, Oldenburg HS, Peterse JL, Bartelink H, Rutgers EJ (2008) Clinical outcome after selective treatment of patients diagnosed with ductal carcinoma in situ of the breast. Ann Surg Oncol 15(1):235-243

Meropol NJ, Schrag D, Smith TJ, Mulvey TM, Langdon RM, Jr, Blum D, et al. (2009) American society of clinical oncology guidance statement: the cost of cancer care. J Clin Oncol 27(23):3868-3874

Ministério_Saúde_Brasil (2009) Diretrizes Metodológicas - Estudos de Avaliação Ecônomica de Tecnologias em Saúde, T.e.l.E. Secretária de Ciência. Ministério da Saúde, Brazil

Ministério_Saúde_Brasil, DATASUS (2011). http://www2.datasus.gov.br/DATASUS/ index.php

Mook S, Van't Veer $\amalg$, Rutgers EJ, Ravdin PM, van de Velde AO, van Leeuwen FE, et al. (2011) Independent prognostic value of screen detection in invasive breast cancer. J Natl Cancer Inst 103(7):585-597

Moss SM, Cuckle H, Evans A, Johns L, Waller M, Bobrow L (2006) Effect of mammographic screening from age 40 years on breast cancer mortality at 10 years' follow-up: a randomised controlled trial. Lancet 368(9552):2053-2060

Mouridsen H, Gershanovich M, Sun Y, Perez-Carrion R, Boni C, Monnier A, et al. (2001) Superior efficacy of letrozole versus tamoxifen as first-line therapy for postmenopausal women with advanced breast cancer: results of a phase III study of the International Letrozole Breast Cancer Group. J Clin Oncol 19 (10):2596-2606

Mouridsen H, Gershanovich M, Sun Y, Perez-Carrion R, Boni C, Monnier A, et al. (2003) Phase III study of letrozole versus tamoxifen as first-line therapy of advanced breast cancer in postmenopausal women: analysis of survival and update of efficacy from the International Letrozole Breast Cancer Group. J Clin Oncol 21(11):2101-2109

MS B (2011) Avaliação do funcionamento dos mamográfos no âmbito do Sistema Único de Saúde - Grupo Nacional Força Tarefa, D.N.d.A.d. SUS, Editor, Brasilia, DF, Brasil

Nelson HD, Tyne K, Naik A, Bougatsos C, Chan BK, Humphrey L (2009) Screening for breast cancer: an update for the U.S. Preventive Services Task Force. Ann Intern Med 151(10):727-737. W237-242

Okonkwo QL, Drasma G, der Kinderen A, Brown ML, de Koning HJ (2008) Breast cancer screening policies in developing countries: a cost-effectiveness analysis for India. J Natl Cancer Inst 100(18):1290-1300

Perez EA, Romond EH, Suman VJ, Jeong JH, Davidson NE, Geyer CE, Jr, et al. (2011) Four-year follow-up of trastuzumab plus adjuvant chemotherapy for operable human epidermal growth factor receptor 2-positive breast cancer: joint analysis of data from NCCTG N9831 and NSABP B-31. J Clin Oncol 29(25):3366-3373

Peto R, Davies C, Godwin J, Gray R, Pan HC, Clarke M, et al. (2012) Comparisons between different polychemotherapy regimens for early breast cancer: meta-analyses of long-term outcome among 100,000 women in 123 randomised trials. Lancet 379(9814):432-444

Pisano ED, Hendrick RE, Yaffe MJ, Baum JK, Acharyya S, Cormack JB, et al. (2008) Diagnostic accuracy of digital versus film mammography: exploratory analysis of selected population subgroups in DMIST. Radiology 246(2):376-383

Rojnik K, Naversnik K, Mateovic-Rojnik T, Primiczakelj M (2008) Probabilistic cost-effectiveness modeling of different breast cancer screening policies in Slovenia. Value Health 11(2):139-148

Schopper D, de Wolf C (2009) How effective are breast cancer screening programmes by mammography? Review of the current evidence. Eur J Cancer 45(11):1916-1923

Skaane P, Hofvind S, Skjennald A (2007) Randomized trial of screen-film versus full-field digital mammography with soft-copy reading in population-based screening program: follow-up and final results of Oslo II study. Radiology 244(3):708-717

Slamon DJ, Leyland-Jones B, Shak S, Fuchs H, Paton V, Bajamonde A, et al. (2001) Use of chemotherapy plus a monoclonal antibody against HER2 for metastatic breast cancer that overexpresses HER2. N Engl J Med 344 (11):783-792

Smith RA, Duffy S (2011) Over diagnosis in breast cancer screening: methodological considerations of current estimates. Supplement to Cancer Research 71(24):658

Souza FH (2012) Mamografia Digital em Comparação com Mamografia Convencional no Rastreamento do Câncer de Mama no Brasil: Revisão Sistemática, Custo da Doença e Análise de Custo-Efetividade no Sistema Único de Saúde. Thesis (PhD in Epidemiology), Federal University of Rio Grande do Sul (UFRGS), Porto Alegre, Brazil

Souza FH, Wendland EM, Rosa MI, Polanczyk (2013) Full-field digital mammography is not more accurate than screen-film mammography in population screening: a systematic review and meta-analysis. Breast 22(3):217-224

Szeto KL, Devlin NJ (1996) The cost-effectiveness of mammography screening: evidence from a microsimulation model for New Zealand. Health Policy 38(2):101-115

Tabar L, Dean PB (2008) Thirty years of experience with mammography screening: a new approach to the diagnosis and treatment of breast cancer. Breast Cancer Res 10(Suppl 4):S3

Tice JA, Feldman MD (2008) Full-field digital mammography compared with screen-film mammography in the detection of breast cancer: rays of light through DMIST or more fog? Breast Cancer Res Treat 107(2):157-165

Tosteson AN, Stout NK, Fryback DG, Acharyya S, Herman BA, Hannah LG, et al. (2008) Cost-effectiveness of digital mammography breast cancer screening. Ann Intern Med 148(1):1-10

US Preventive Services Task Force (2009) Screening for breast cancer: U.S Preventive services task force recommendation statement. Ann Intern Med 151(10):716-726. W-236

van Oortmarssen GJ, Habbema JD, van der Maas PJ, de Koning HJ, Collete HJ, Verbeek AJ, et al. (1990) A model for breast cancer screening. Cancer 66 (7):1601-1612

Vanni T, Legood R, White RG (2010) Calibration of disease simulation mode using an engineering approach. Value in Health 13(1):157 
Vanni T, Luz PM, Grinsztejn B, Veloso VG, Foss A, Mesa-Frias M, et al. (2012) Cervical cancer screening among HIV-infected women: an economic evaluation in a middle-income country. Int J Cancer 131(2):E96-E104

Wapnir IL, Anderson SJ, Mamounas EP, Geyer CE, Jr, Jeong JHTan-Chiu E, et al. (2006) Prognosis after ipsilateral breast tumor recurrence and loco regional recurrences in five national surgical adjuvant breast and bowel project node-positive adjuvant breast cancer trials. J Clin Oncol 24(13):2028-2037

Wapnir IL, Dignam JJ, Fisher B, Mamounas EP, Anderson SJ, Julian TB, et al. (2011) Long-term outcomes of invasive ipsilateral breast tumor recurrences after lumpectomy in NSABP B-17 and B-24 randomized clinical trials for DCIS. J Natl Cancer Inst 103(6):478-488

World Health Organization (2001) Commission on macroeconomics and health: investing in health for economic development. World Health Organization, Geneva

doi:10.1186/2193-1801-2-366

Cite this article as: Souza and Polanczyk: Is Age-targeted full-field digital mammography screening cost-effective in emerging countries? A micro simulation model. SpringerPlus 2013 2:366.

\section{Submit your manuscript to a SpringerOpen ${ }^{\circ}$} journal and benefit from:

- Convenient online submission

- Rigorous peer review

- Immediate publication on acceptance

- Open access: articles freely available online

- High visibility within the field

- Retaining the copyright to your article

Submit your next manuscript at $>$ springeropen.com 